\title{
Transformações do uso e cobertura da terra na estação metroviária de Campo Limpo - SP
}

\author{
Land use/cover changes at the Campo Limpo subway station - SP
}

William Pereira de Lima ', Alfredo Pereira de Queiroz"

\begin{abstract}
RESUMO
As estações ferroviárias exercem grande influência no ambiente urbano. A magnitude do seu impacto, no entanto, pode ser considerada variável. O trabalho analisa as mudanças no uso e cobertura da terra no entorno da estação do Metrô Campo Limpo, inaugurada em 2002 em São Paulo. A classificação da imagem de satélite de 2002 e da ortofoto de 2010, os dados do censo demográfico e dos lançamentos imobiliários foram utilizados para analisar a cobertura e variação populacional. Constatou-se pequena variação das classes na área mais próxima ao Metrô (até $600 \mathrm{~m}$ ), mas significativa variação entre 600 e 1000m. As maiores transformações foram: vegetação arbórea $(+4,89 \%)$, telhado de concreto $(+4,54 \%)$, sombra $(-7,42 \%)$ e solo exposto (-5,77\%). A elevação do número de lançamentos imobiliários, principalmente em 2001, foi observada, mas com redução da área útil e do preço do metro quadrado dos imóveis. Ainda que a expectativa de mudanças no uso e cobertura da terra seja elevada após a construção de uma estação, o mapeamento do entorno imediato do Metrô Campo Limpo indicou variação um pouco abaixo do esperado.
\end{abstract}

Palavras-chave: Acessibilidade; Classificação Por Regiões; Cobertura Da Terra; Metrô

\section{ABSTRACT}

Railway stations have a major influence on the urban environment. The magnitude of its impact, however, can be considered variable. This paper analyzes changes in land use and land cover around the Campo Limpo subway station, which opened in 2002 in São Paulo. The satellite image classification of 2002 and the 2010 orthophoto, census data and property launches were used to analyze coverage and population variations. There was a small variation of classes in the area closest to the subway (up to $600 \mathrm{~m}$ ), but significant variation between 600 and $1000 \mathrm{~m}$. The major changes were: tree vegetation $(+4.89 \%)$, concrete roof $(+4.54 \%)$, shade $(-7.42 \%)$ and exposed soil $(-5.77 \%)$. The increase in the number of real estate launches, mainly in 2001, was observed, but with a reduction in the useful area and the square meter price of the real estate. Although the expectation of changes in land use and coverage is high after the construction of a station, the mapping of the immediate surroundings of the Campo Limpo subway indicated variation slightly below expectations.

Keywords: Accessibility; Classification By Regions; Land Cover; Subway

Instituto Socioambiental E-mail: willplima@gmail.com ORCID: https://orcid.org/0000-0002-9976-4582

" Departamento de Geografia, FFLCH USP. E-mail: aqueiroz@usp.br ORCID: https://orcid.org/0000-0003-4038-4953 


\section{INTRODUÇÃO}

A acessibilidade aos transportes é conhecida por ser um elemento crucial na determinação dos padrões e transformações urbanos (SONG; KIM, 2015). As relações entre meios de transporte e o uso da terra, no entanto, nem sempre são unidirecionais, mas complexas e interdependentes (YIGITCANLAR; KAMRUZZAMAN, 2014).

Segundo Du; Mulley (2007), novas linhas ferroviárias urbanas apresentam uma grande capacidade de atrair a população e as empresas, em decorrência da facilidade de acesso. Contudo, a acessibilidade é apenas um dos fatores que influenciam o crescimento urbano. Deve também ser considerada em conjunto com o mercado imobiliário regional, disponibilidade de terrenos, mudanças nas frotas de veículos, declínio urbano nos centros das cidades e qualidade da conexão da estação ao centro da cidade.

A infraestrutura metroviária, no entanto, transcende a sua presença física no ambiente urbano. Sua implantação depende de um conjunto de componentes estatutários e legais, como marcos regulatórios, legislação específica, desapropriações, alienação de terrenos, servidão, entre outros (DARROCH; BEECROFT; NELSON, 2016).

O desenvolvimento de novos sistemas de transporte frequentemente causa mudanças demográficas e socioeconômicas na área de implantação. Entretanto, a extensão e os tipos de impactos variam, pois dependem dos padrões de assentamentos existentes, condições socioeconômicas e objetivos do projeto (CALVO; OÑA; ARÁN, 2013).

De acordo com Villaça (1978), se o transporte é responsável por diminuir as distâncias e o tempo gasto para chegar ao lugar desejado, consequentemente ele pode trazer mudanças nos padrões da estrutura urbana e nos arranjos internos dos usos da terra. Assim, considera-se que a acessibilidade ao transporte constitui um papel determinante na definição do uso e preço da terra, por envolver um bem fundamental para os habitantes de grandes centros urbanos: o tempo de deslocamento.

Nesse contexto, o objetivo da pesquisa é analisar as transformações na cobertura da terra no entorno da estação metroviária do Campo Limpo, inaugurada em 2002, no 
município de São Paulo. Para tanto, as coberturas da terra, extraídas da classificação da imagem de satélite de 2002 e da ortofoto de 2010, foram identificadas e, seus resultados, relacionados aos dados populacionais e aos lançamentos imobiliários residenciais em um Sistema de Informações Geográficas.

\section{REFERENCIAL TEÓRICO}

\subsection{Sensoriamento Remoto}

Sensoriamento Remoto pode ser definido como a conjunto de tecnologias que visam obter de imagens da superfície terrestre por meio da detecção e quantificação das interações da radiação eletromagnética com os componentes terrestres (MENESES; ALMEIDA, 2012, NOVO; PONZONI, 2001).

O Sensoriamento Remoto, lato sensu, possui duas principais etapas: a primeira diz respeito à aquisição de dados através de sensores acoplados em aviões ou satélites e, a segunda, está relacionada à interpretação humana dos dados e extração de informações dos objetos e feições (LUCHIARI, 2004).

O avanço das tecnologias dos sensores orbitais pode ser considerado como uma resposta ao nível de detalhamento necessário aos estudos intraurbanos, juntamente com novos métodos semiautomáticos para a extração de informações, como, por exemplo, a cobertura da terra (ARAUJO; LUCHIARI, 2016).

De acordo com Avelar; Zah e Tavares (2009), o Sensoriamento Remoto é fundamental para a obtenção de dados espaciais em áreas que apresentam elevada dinâmica de modificações urbanas. Nesse contexto de transformações, dados atualizados da cobertura da terra são essenciais para o planejamento urbano (LIU et al. 2017, STÜRCK et al. 2015).

Nos estudos intraurbanos, as fotografias aéreas são muito utilizadas, pois seu nível de detalhamento permite visualizar padrões vinculados à cobertura da terra e à disposição das heterogêneas formas urbanas. Imagens orbitais também são muito úteis, pois permitem o registro da dinâmica da expansão de manchas urbanas (VOLPE, 2009) e podem fornecer, 
periodicamente, informações sobre o tecido urbano e a tendência do seu crescimento (LOMBARDO; MACHADO, 2011).

As imagens orbitais de alta resolução espacial são recorrentemente utilizadas para os estudos urbanos. Possibilitam avaliações qualitativas, como a interpretação visual da morfologia dos objetos, e quantitativas, pela exploração dos níveis de cinza dos pixels. Entretanto, as características dos materiais empregados nas construções, como forma, altura e arranjo, e eventual similaridade espectral dos alvos, podem dificultar sua classificação (SOUSA, 2012).

\subsection{Influência das estações}

Os impactos dos empreendimentos ferroviários foram avaliados por inúmeros pesquisadores e em distintos países. Pagliara; Papa (2011) compararam os preços dos imóveis e o crescimento da população nos distritos atendidos por novas linhas ferroviárias, e nos distritos de controle, em Nápoles. Para os autores, os impactos da construção de um sistema ferroviário sobre a população variaram conforme a localização específica das estações e a própria rede. Em quase todos os casos avaliados, o novo transporte público elevou o valor das propriedades, mas o percentual de aumento variou substancialmente e dependeu de condições locais específicas.

Para Cervero; Duncan (2002), o estabelecimento de uma linha férrea urbana poderia aumentar o valor das casas em até $25 \%$ no condado de Santa Clara, Califórnia. Segundo Hess (2007), o valor de uma casa localizada perto de uma estação em Buffalo, Nova York, poderia estar 5\% acima da média da cidade. Du; Mulley (2007) constataram que o valor da propriedade servida pela nova linha Victoria, em Londres, aumentou 5\% em relação às áreas não atendidas pela linha. Em Madri, a proximidade de estações da linha Metrosur causou um impacto positivo na venda de imóveis e o valor da propriedade diminuiu conforme o aumento da distância das estações de transporte ferroviário (DORANTES; PAZ; VASSALO, 2011).

Song; Kim (2015) constataram uma significativa relação causal entre a acessibilidade do metrô e a elevação do valor das locações, na região metropolitana de Seul, mas uma 
relação relativamente fraca entre a distribuição da população e a acessibilidade do metrô. Consideraram que as relações entre essas variáveis foram mais complexas do que o previsto, pois estariam sujeitas aos contextos regionais.

Para a cidade de Nanjing, Zhao et al., (2011) consideraram que ao menos 10 variáveis poderiam influenciar o número de passageiros da estação de metrô: população, emprego, área residencial, número de escolas, locais de entretenimento, shopping centers, comprimento das vias, linhas de ônibus, espaços de bicicletas e transferência de variáveis dummy (variável qualitativa convertida em quantitativa).

Dentre as pesquisas brasileiras, Macêdo (2010) investigou a transformação do uso da terra causada pelo aumento da acessibilidade por linhas de Metrô em São Paulo. A autora analisou os entornos das estações das linhas Vermelha, Verde e Azul para averiguar os impactos dos empreendimentos verticais e a variação das áreas construídas. O resultado indicou o crescimento da atuação imobiliária nos arredores da estação, nos cinco primeiros anos após sua abertura. O aumento das construções verticais e a queda nos usos residenciais horizontais também foram observados.

A pesquisa de Nigriello (1977) analisou a área de um quilômetro ao redor da linha 1 Azul (Norte-Sul) em São Paulo. As variáveis consideradas foram o nível de renda dos habitantes, as restrições de uso, a ocupação do solo, a avaliação do entorno físico, os serviços e equipamentos oferecidos no local - além da própria acessibilidade - antes e depois da construção do Metrô. Após a correlação estatística dos dados, concluiu que, de maneira geral, há uma relação diretamente proporcional entre acessibilidade e o valor do preço da terra. Constatou que o valor do imóvel tende a diminuir quando há dificuldade para acessar o centro da cidade.

A influência da estação do Metrô no aumento das construções imobiliárias não é, porém, uma relação direta e simples de ser mensurada. Ambas as autoras citadas destacam que a acessibilidade e o uso da terra possuem inúmeras facetas. Influências relacionadas à especulação imobiliária, à interferência do Estado (investimentos públicos) e ao 
ordenamento jurídico (ex.: lei do zoneamento), também são parâmetros importantes nas mudanças no uso da terra.

\section{METODOLOGIA}

\subsection{Periodicidade da análise e área de influência dos empreendimentos}

A construção de cenários permite interpretar as mudanças das funções e das interações entre os elementos urbanos (SANTOS, 2004). De acordo com Arw et al. (2002), a análise desses cenários deve ser realizada em três períodos distintos: antes da decisão de construir o empreendimento, imediatamente após sua instalação e nos anos posteriores. Cervero (1994) considerou adequado o intervalo de cinco anos para detectar mudanças no raio de influência direta do empreendimento.

A adoção de raios ou polígonos ao redor do objeto de pesquisa é muito útil para compreender e representar a dinâmica das transformações urbanas (SANTOS, 2004). Muitos estudos usam limiares de distância para delimitar a área de influência da estação ferroviária. Distâncias euclidianas ou de redes, entre $400 \mathrm{~m}$ e $800 \mathrm{~m}$, são usuais por causa do tempo de caminhada. Diferentes faixas são utilizadas, pois dependem do tipo de trânsito e características urbanas, como as variáveis socioeconômicas e de uso da terra (JUN et al., 2015).

Lima Neto (2011) analisou dados dos imóveis localizados em um raio de 500 metros das estações do sistema metroviário do Distrito Federal, entre 2003 e 2010. Destacou duas características: a proximidade da estação e o potencial uso do terreno. A distância influenciou o valor dos diferentes tipos de usos: quanto mais perto, maior a variação de preço. A valorização teria um limite de influência, que pode variar entre 300 e 500 metros, dependendo dos efeitos negativos da estação, como o aumento do ruído e do trânsito. A segunda estaria relacionada com a legislação de uso e ocupação. Se a área for residencial e muito próxima à estação, a valorização poderia ser menor se comparada às áreas de usos mistos e comerciais. 
Para Gonçalves; Portugal (2008), a influência da estação pode ser medida pelo tempo de 10 minutos de caminhada ou pela distância de 500 metros. Destacam, no entanto, que elementos como a declividade e rede hidrográfica podem interferir nessa relação "tempo $\mathrm{x}$ distância". Macêdo (2010), entretanto, optou pelo raio de 600 metros ao redor das estações metroviárias para avaliação dos impactos na área urbana.

Assim, os autores definiram como área de influência o raio de $600 \mathrm{~m}$ ao redor da estação de Metrô do Campo Limpo. Também foi estabelecido um raio de 1000m, caracterizado como área de controle, para comparar os lançamentos imobiliários residenciais e a verticalização do entorno.

\section{2 Área de Estudo}

Inserida na faixa de fronteira de três distritos da cidade de São Paulo - Campo Limpo (50\%), Capão Redondo (40\%) e Jardim São Luís (10\%), a área de estudo foi delimitada por um raio de 600 metros a partir da estação do Metrô Campo Limpo, Linha 5-Lilás (figura 1), inaugurada em 20/10/2002. 
Figura 1 - Localização da área de estudo

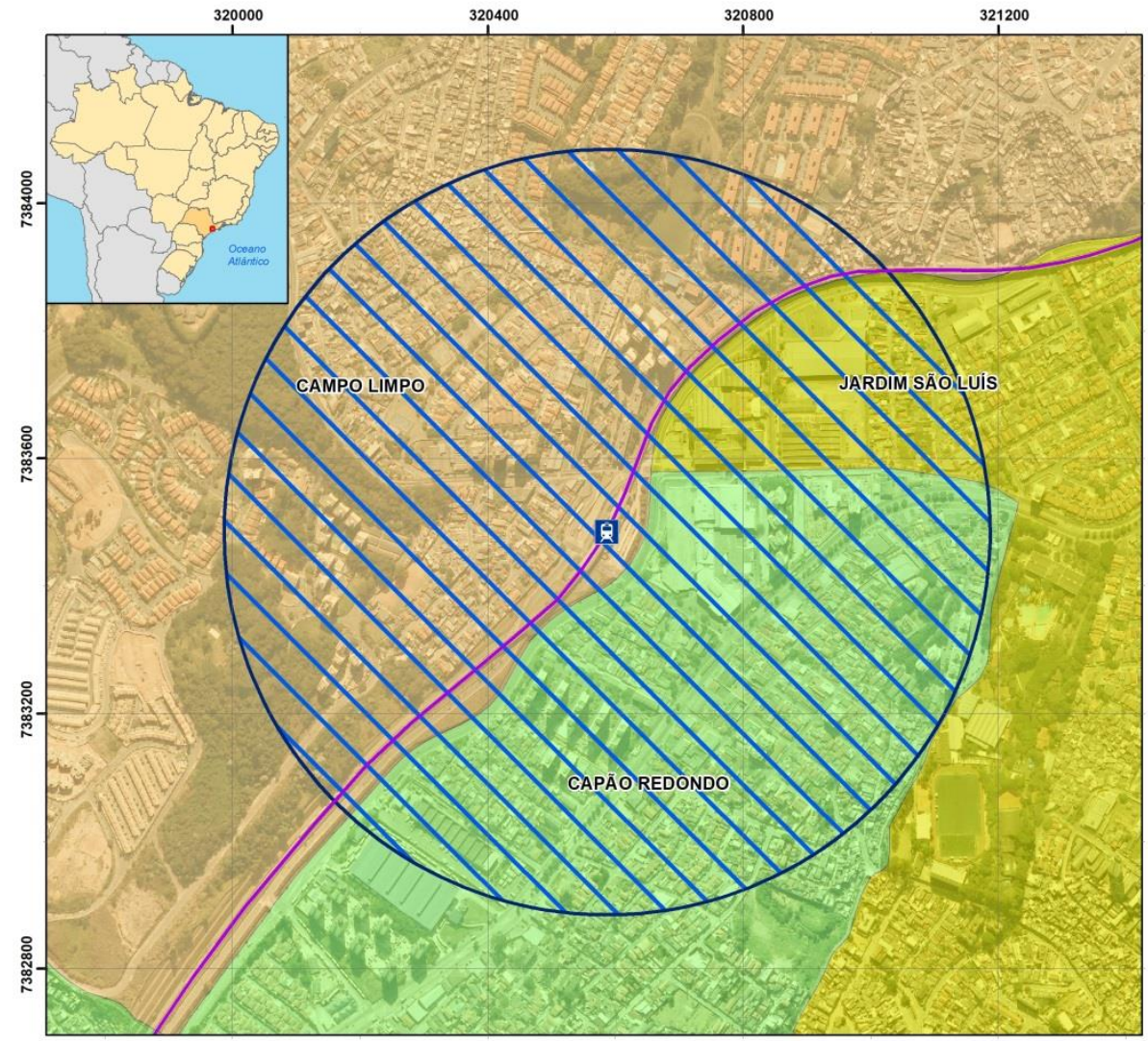

\section{Localização da \\ Área de Estudo}
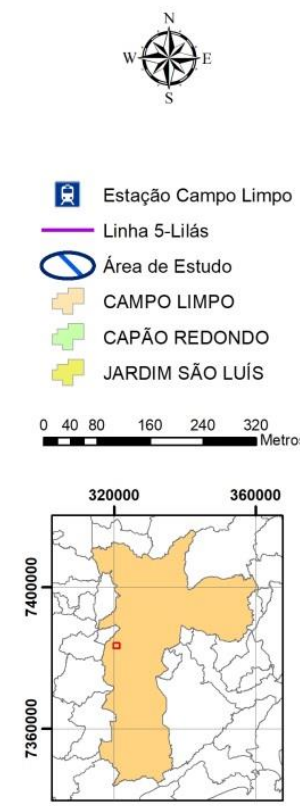

Projeçăo Universal Transversa de Mercator
Fuso 23 S - Datum Horizontal. SIRGAS 2000 Fonte de dados: Prefeitura de São Paulo, 2014: IBGE, 2010; EMPLASA, 2010/2011

Fonte: Organização dos autores

A linha Lilás 5 do Metrô de São Paulo atende à zona sul da cidade, passando pelos distritos de Capão Redondo, Campo Limpo, Jardim São Luís, Vila Andrade, Santo Amaro, Campo Belo, Itaim Bibi, Moema e Vila Mariana. Possui 17 estações (figura 2), extensão de 19,9 quilômetros e pode transportar 855 mil passageiros por dia.

Figura 2 - Representação da linha 5 Lilás do Metrô de São Paulo

\section{MAPA DAS ESTAÇÕES}

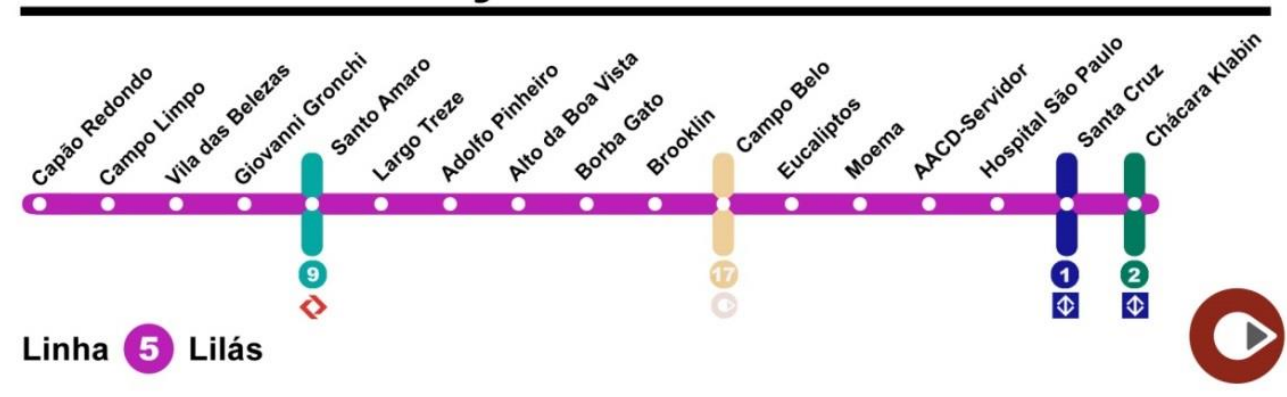

Fonte: Metrô de São Paulo 
O cronograma de inaugurações das estações sofreu atrasos e, em 2018, sua operação foi concedida ao consórcio Via Mobilidade. O trecho entre a Estação Capão Redondo e Largo Treze (06 estações) foi inaugurado em 2002. Em 2014, foi aberta a Estação Adolfo Pinheiro. Em 2017, as estações Alto da Boa Vista, Borba Gato e Brooklin começaram a funcionar. Em 2018, foram abertas as estações Eucaliptos, Moema e AACD-Servidor, Hospital São Paulo, Santa Cruz e Chácara Klabin. Em 2019, a última estação, Campo Belo, foi inaugurada.

\subsection{Materiais e métodos}

Os programas SPRING 5.3, ArcGis 10.1 e Excel foram utilizados no processamento e análise dos seguintes dados:

- Mosaico colorido de imagens do satélite IKONOS II, bandas RGB, de outubro de 2002, fusionado com a banda pancromática, com resolução espacial de 1 metro e resolução radiométrica de 11 bits. A imagem foi pré-processada com um Modelo Digital de Terreno de resolução espacial de 5 metros e reprojetado para o sistema SIRGAS 2000 (projeção UTM, zona 23S);

- Ortofoto colorida (RGB) produzida pela Empresa Paulista de Planejamento Metropolitano S/A (EMPLASA) entre os anos 2010 e 2011 (projeto Mapeia São Paulo). Possui 1 metro de resolução espacial e foi previamente ortorretificada com um Modelo Digital de Terreno (projeção UTM, zona 23S, SIRGAS 2000). Acurácia posicional planialtimétrica compatível com a escala 1:10.000 (Classe A do Padrão de Exatidão Cartográfico);

- Dados do Censo do IBGE de 1991, 2000 e 2010;

- Dados dos lançamentos imobiliários residenciais de 1985 a 2011 do Centro de Estudos da Metrópole - CEM.

O fluxograma das atividades da pesquisa está representado pela figura 3. 
Figura 3 - Fluxograma de trabalho

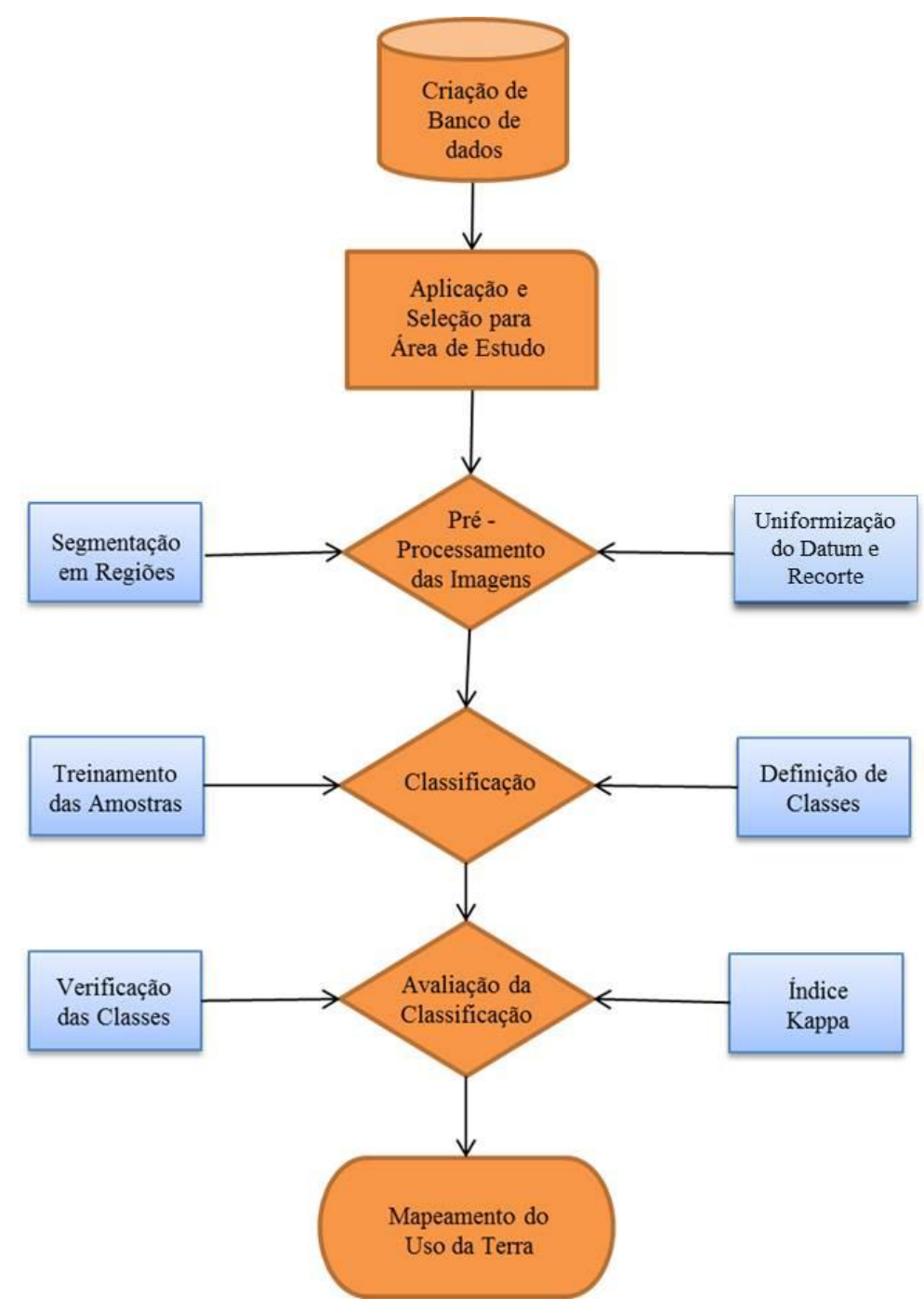

Fonte: Organização dos autores

Após a identificação das características e feições urbanas da área de estudo, em escala local, foram definidas nove classes de uso da terra (figura 4). Considerando também a representatividade dos materiais empregados no ambiente urbano, foram estabelecidas as seguintes classes: vegetação arbórea, vegetação rasteira, corpos d'água, solo exposto, sombra, asfalto, cobertura de cerâmica, cobertura de amianto/concreto e cobertura de metal. 
Figura 4 - Chave de classificação e características dos objetos mapeados

\begin{tabular}{|c|c|c|c|c|}
\hline $\begin{array}{c}\text { Nivel de } \\
\text { Classificação }\end{array}$ & $\begin{array}{l}\text { Tipo de } \\
\text { Cobertura }\end{array}$ & \begin{tabular}{|c|} 
Classes de \\
Cobertura \\
do Solo
\end{tabular} & Visualização & Características \\
\hline \multirow{4}{*}{$\begin{array}{l}\text { Área Urbana ou } \\
\text { Construída }\end{array}$} & \multirow{3}{*}{ Edificaçốes } & $\begin{array}{l}\text { Telhado de } \\
\text { Cerâmica }\end{array}$ & & $\begin{array}{c}\text { Cor: tons de larania de claros a } \\
\text { escuros. Há sombras, outras } \\
\text { coberturas e asfalto no entorno, } \\
\text { possuem textura rugosa e formas } \\
\text { retangulares }\end{array}$ \\
\hline & & $\begin{array}{c}\text { Telhado de } \\
\text { Concreto }\end{array}$ & & $\begin{array}{l}\text { Cor: podem ser escuros (cinza) ou } \\
\text { claros (viriaçôes de branco). Ledeado } \\
\text { por sombras e podem variar de } \\
\text { textura lisa a rugosa a depender do } \\
\text { tipo. Tamanhos variados. }\end{array}$ \\
\hline & & $\begin{array}{l}\text { Telhado de } \\
\text { Metal }\end{array}$ & & $\begin{array}{l}\text { Cor: tons de azul. Rodeado por } \\
\text { sombras e próximos a eixos viários. } \\
\text { Textura lisa e forma retangular. }\end{array}$ \\
\hline & Pavimentação & Asfalto & & $\begin{array}{l}\text { A cor pode variar do cinza claro ao } \\
\text { escuro. Tem textura lisa e formas } \\
\text { alongadas, retangulares e quadradas } \\
\text { (estacionamentos]. Próximo à } \\
\text { diversas coberturas. }\end{array}$ \\
\hline \multirow{2}{*}{ Florestas } & \multirow{2}{*}{ Vegetação } & Árbórea & & $\begin{array}{c}\text { Possuem diferentes variaçóes de } \\
\text { tons de verde, textura rugosa, com } \\
\text { formas diferentes a depender do } \\
\text { tamanho. Geralmente estão cercadas } \\
\text { por sombras. }\end{array}$ \\
\hline & & Rasteira & & $\begin{array}{c}\text { Cor do verde médio a claro. Com } \\
\text { textura rugosa e forma irregular, é } \\
\text { rodeada por diversas coberturas } \\
\text { entre elas vegetaçấo árborea e solo } \\
\text { exposto. }\end{array}$ \\
\hline Corpos D' Água & Água & $\begin{array}{l}\text { Corpos } D^{\prime} \\
\text { Agua }\end{array}$ & & $\begin{array}{l}\text { Cor: varia de verde escuro (lago) a } \\
\text { azul claro (piscinass. A t textura é lisa, } \\
\text { mas a forma pode ser curvenilea no } \\
\text { primeiro caso e retangular no } \\
\text { segundo. Da mesma forma, pode } \\
\text { estar proximas à vegetação rasteira } \\
\text { ou a coberturas de concreto. }\end{array}$ \\
\hline Terra Estéril & Solo Exposto & Solo Exposto & & $\begin{array}{l}\text { A cor varia do amarelo claro ao } \\
\text { vermelho médio, semelhante à } \\
\text { ferrugem. Tem textura lisae e } \\
\text { diversas formas como o predomínio } \\
\text { da retangular. É rodeada por } \\
\text { vegetą̧âa rasteira, asfalto ou outras } \\
\text { coberturas. }\end{array}$ \\
\hline Outros & Sombra & Sombra & & $\begin{array}{l}\text { Possui cor preta e textura lisa. } \\
\text { Variam de acordo como o objeto que } \\
\text { as represntam. }\end{array}$ \\
\hline
\end{tabular}

Fonte: Organização dos autores

O software Spring 5.3 foi utilizado para a segmentação e classificação das imagens. De acordo com Brites et al. (2012), a segmentação de imagens pode ser definida como o processo de agrupamento de pixels que possuem características semelhantes. O algoritmo utilizado foi o de crescimento de regiões. Seus dois principais parâmetros são: limiar de similaridade, que indica a semelhança entre o pixel candidato à inclusão em um determinado grupo e os parâmetros estatísticos referentes aos pixels que já fazem parte desse segmento; e tamanho mínimo dos polígonos gerados, que define o número mínimo de pixels dos segmentos. Os limiares adotados foram compatíveis com os propostos por Souza et al. (2003): 15 para similaridade e 50 para a área. 
A Classificação foi realizada pelo algoritmo supervisionado Bhattacharya. Conforme Brites et al. (2012), a distância Bhattacharyya mede a separabilidade estatística entre um par de classes espectrais (distância média entre as distribuições de probabilidades de classes espectrais). Essa classificação foi adotada, pois considera não só a variação espectral dos pixels, como também a textura do objeto e sua relação espacial com os demais elementos da imagem.

$\mathrm{Na}$ classificação, constatou-se significativa confusão entre as classes asfalto e concreto. Para minimizar o problema, o arquivo vetorial da rede viária, de 2014, foi sobreposto às imagens classificadas de 2002 e 2010. As vias foram usadas como referência para melhorar a acurácia da classificação. Os polígonos de concreto contidos majoritariamente no leito carroçável das vias $\left(=>60 \mathrm{~m}^{2}\right)$ foram avaliados visualmente e, dependendo das circunstâncias, incorporados à classe asfalto. Entretanto, nem todos os polígonos puderam ser realocados de classe. As duas principais razões para manter a classificação original foram: a) sobreposição de sombras, telhados de casas e asfalto, e b) as ruas nos arredores da estação Campo Limpo foram reconfiguradas após o término das obras.

Essa sobreposição foi realizada em analogia aos procedimentos de classificação orientada ao objeto. Embora não seja o caso desta pesquisa, considerou-se que sobrepor as vias se assemelharia, de alguma forma, ao uso de valores elevados de compacidade. Segundo Kressler; Steinnocher (2006), os altos valores de compacidade geram segmentos menores e são usuais quando o objeto a ser classificado possui atributos espectrais conflitantes com outros.

O índice Kappa (CONGALTON; GREEN, 2009) foi utilizado para avaliar a acurácia das classificações. Ainda que o Kappa tenha sido alvo de controvérsia recente, não há registro de indicador com os mesmos predicados para analisar o resultado da classificação. Seu uso permanece muito difundido, pois uma significativa quantidade de pesquisas adota esse coeficiente para avaliar a qualidade das classificações de imagens de Sensoriamento Remoto (ARAUJO; QUEIROZ, 2018). 
Os resultados obtidos em 450 pontos, amostrados aleatoriamente no programa ArcGis, foram de 0,74, na ortofoto de 2010, e de 0,62, na imagem de satélite de 2002. Em relação à proposta de Landis; Koch (1977), como mostra a Tabela 1, concordância foi considerada boa nas duas classificações.

Tabela 1 - Interpretação dos valores do índice kappa

\begin{tabular}{cc}
\hline Valores de kappa & Interpretação \\
\hline$<0$ & Sem concordância \\
$0-0,19$ & Pouca concordância \\
$0,2-0,39$ & Concordância razoável \\
$0,4-0,59$ & Concordância média \\
$0,6-0,79$ & Concordância boa \\
$0,8-1,0$ & Concordância excelente \\
\hline
\end{tabular}

Fonte: Landis; Koch (1977), p. 165.

\section{RESULTADOS}

Os resultados da pesquisa estão sintetizados pelas figuras 5 e 6 . A tabela 2 ilustra a comparação das classes de cobertura da terra (área e porcentual) de 2002 e 2010. Observase que, em 2002, os maiores percentuais de crescimento foram: telhado de concreto/amianto (25,3\%), asfalto (22,6\%) e sombra (21,89\%). Juntas, essas três classes equivalem a mais de dois terços da área de estudo. 
Figura 5 - Classificação da cobertura da terra em 2002

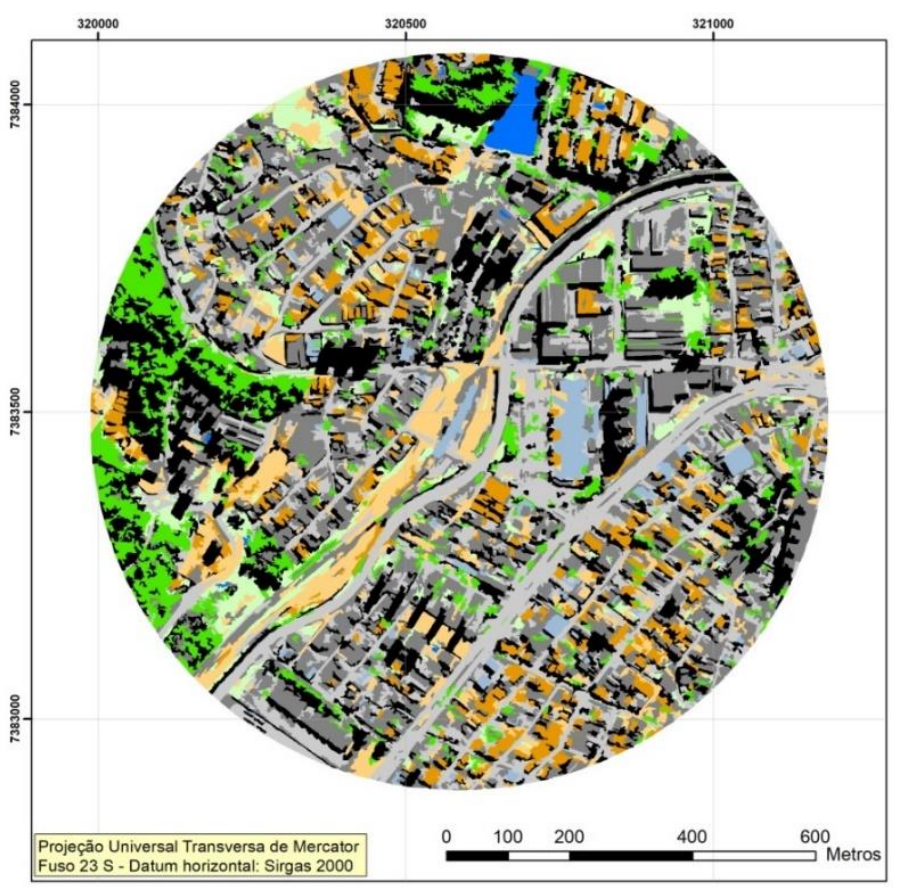

Classificação da Cobertura da Terra 2002<smiles>C1C2C[As]1C2</smiles>

\section{Classes}

Vegetação Arbórea Vegetação Rasteira

Corpos D'Águ

Solo Exposto

Asfalto

Cobertura de Cerâmica

Cobertura de Concreto

Cobertura de Metal

Sombra

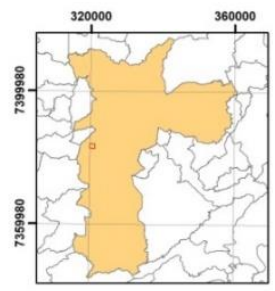

Fonte: Organização dos autores

Figura 6 - Classificação da cobertura da terra em 2010

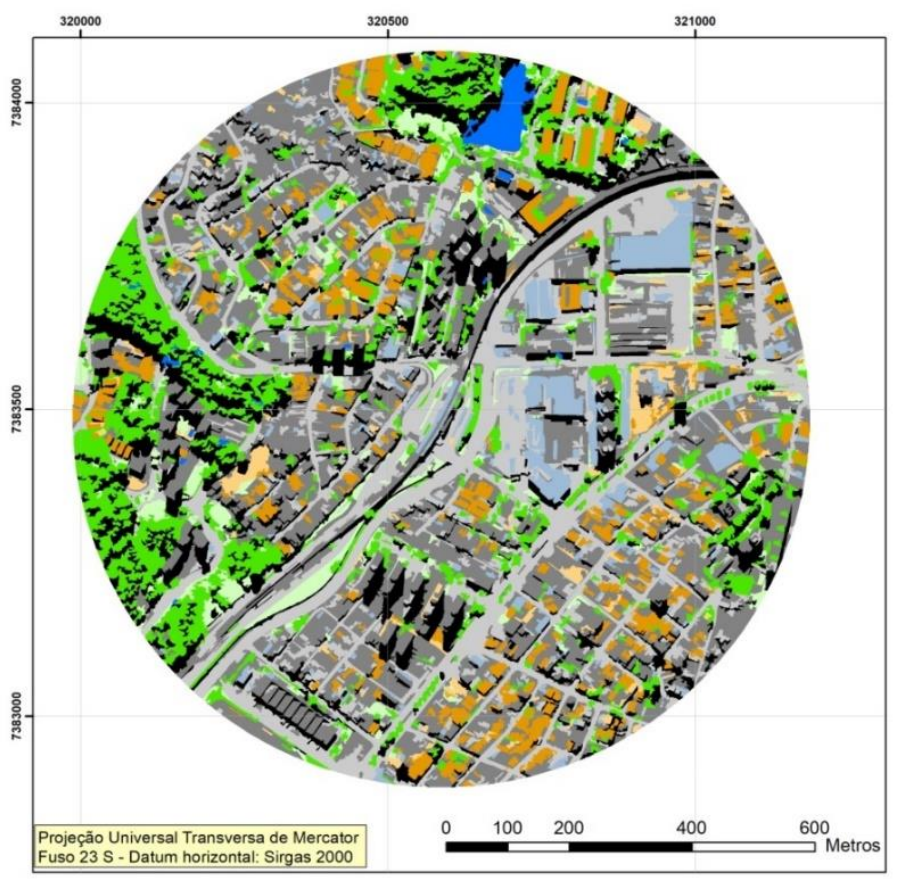

Classificação da Cobertura da Terra 2010

然
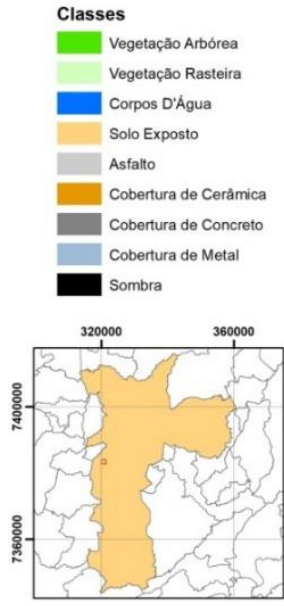

Fonte: Organização dos autores 
Tabela 2 - Comparação das classes das imagens de 2002 e 2010

\begin{tabular}{crrrrr}
\hline Classes & \multicolumn{2}{c}{2002} & & 2010 & \multicolumn{2}{r}{$\begin{array}{r}\text { Incremento } \\
2002-2010 \\
\end{array}$} & área ha & \% área & área ha & \% área & \multicolumn{1}{c}{ (\%) } \\
\hline Vegetação arbórea & 9,21 & 8,14 & 14,74 & 13,04 & 4,89 \\
Vegetação rasteira & 4,83 & 4,28 & 4,09 & 3,62 & $-6,66$ \\
Corpos d'água & 0,80 & 0,71 & 0,97 & 0,86 & 0,15 \\
Solo exposto & 8,74 & 7,73 & 2,22 & 1,96 & $-5,77$ \\
Asfalto & 25,55 & 22,6 & 27,15 & 24,02 & 1,42 \\
Telhado de cerâmica & 7,98 & 7,06 & 8,55 & 7,56 & 0,50 \\
Telhado de concreto & 28,6 & 25,3 & 33,74 & 29,84 & 4,54 \\
Telhado de metal & 2,6 & 2,3 & 5,25 & 4,64 & 2,34 \\
Sombra & 24,74 & 21,89 & 16,35 & 14,46 & $-7,42$ \\
Total & 113,05 & 100,0 & 113,06 & 100,0 & \\
\hline
\end{tabular}

Fonte: Organização dos autores

Percentualmente, a classe sombra foi a que mais perdeu representatividade $(-7,42 \%)$, seguido pela classe solo exposto (-5,77\%). A variação na quantidade de sombras era esperada, pois além das imagens serem sido produzidas e captadas de modo diferente, houve variação da intensidade radiométrica e do ângulo de visão dos sensores. Essas características também podem justificar, em parte, o aumento da vegetação arbórea, pois a maioria das sombras, em 2002, estava próxima a esse tipo de vegetação.

A redução da quantidade de solo exposto está associada à conclusão da estação do Metrô de Campo Limpo. Em 2002, ainda havia obras no canteiro central da Avenida Carlos Caldeira Filho, porém, em 2010, a construção estava concluída. Assim, classe solo exposto foi substituída por asfalto ou vegetação rasteira.

A classe telhado de concreto/amianto se destacou em decorrência da característica residencial da região (acréscimo de 4,54\%). Casas residenciais unifamiliares, condomínios residenciais, edificações que comportam comércios e serviços, além de galpões industriais, são os principais exemplos de usos desta classe na área de estudo. A construção de empreendimentos imobiliários residenciais e o adensamento residencial, ao norte, contribuíram para esse aumento. 
As demais classes (corpos d'água, vegetação rasteira, telhado de cerâmica e asfalto) não apresentaram oscilações significativas (figura 7). Entretanto, a classe telhado de metal, de ocorrência dispersa, aumentou 2,34\%. Considera-se que a construção do shopping Campo Limpo e de outros centros comerciais de menor expressão, que substituíram alguns galpões industriais, seriam os responsáveis por essa alternância de área.

Figura 7 - Comparação entre classes por ano

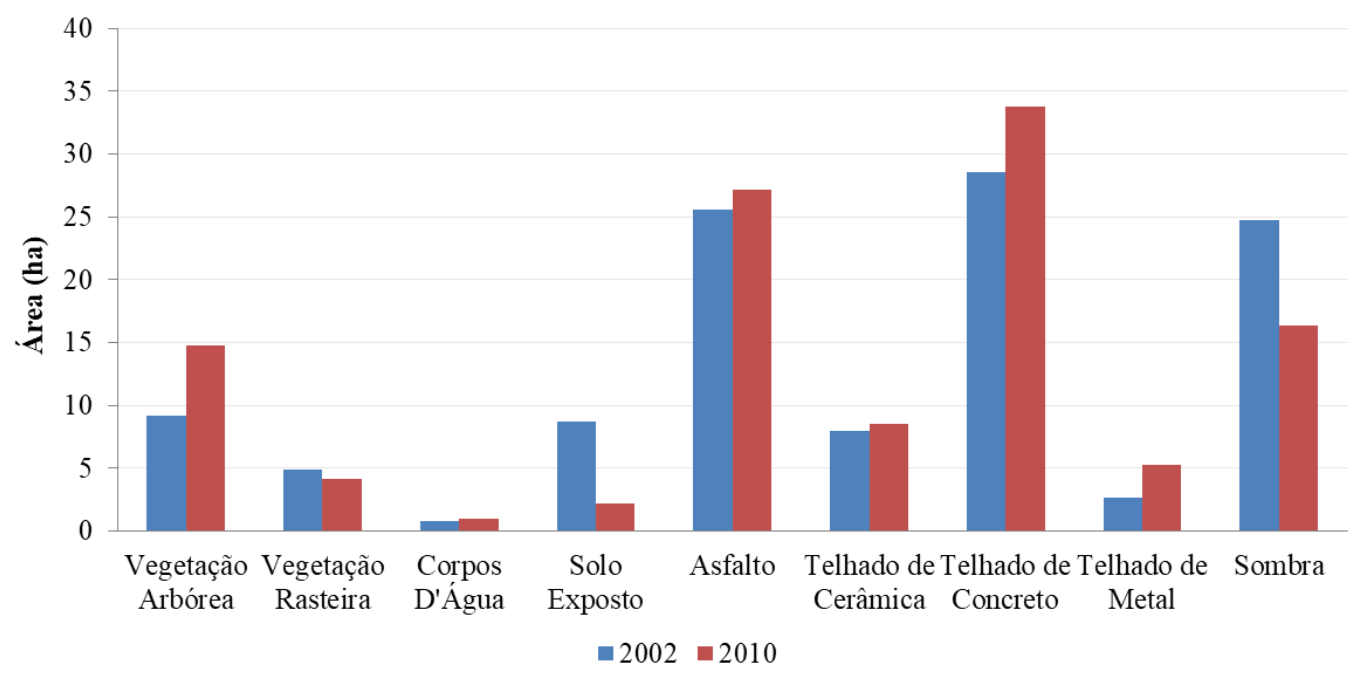

Fonte: Organização dos autores

A figura 8 apresenta a variação da quantidade de habitantes residentes por setor censitário. A inclusão de dados do ano de 1991 serviu como parâmetro comparativo, pois corresponde ao momento anterior à decisão de construir a estação Campo Limpo. 


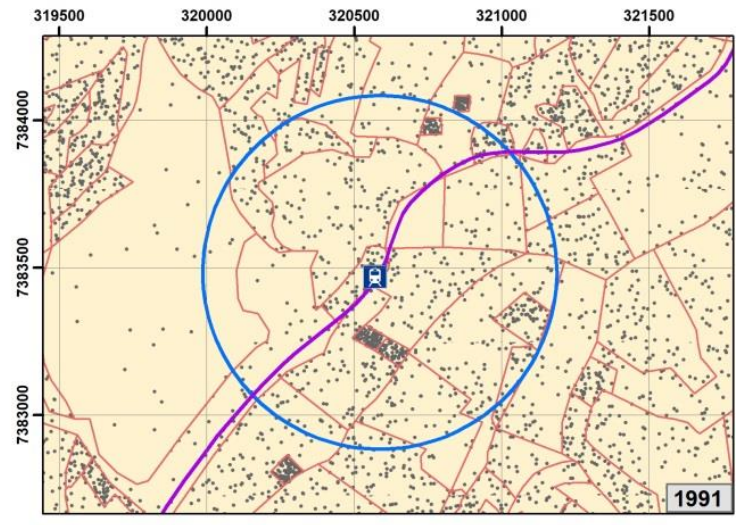

\section{Quantidade de Pessoas Residentes por Setores Censitários}
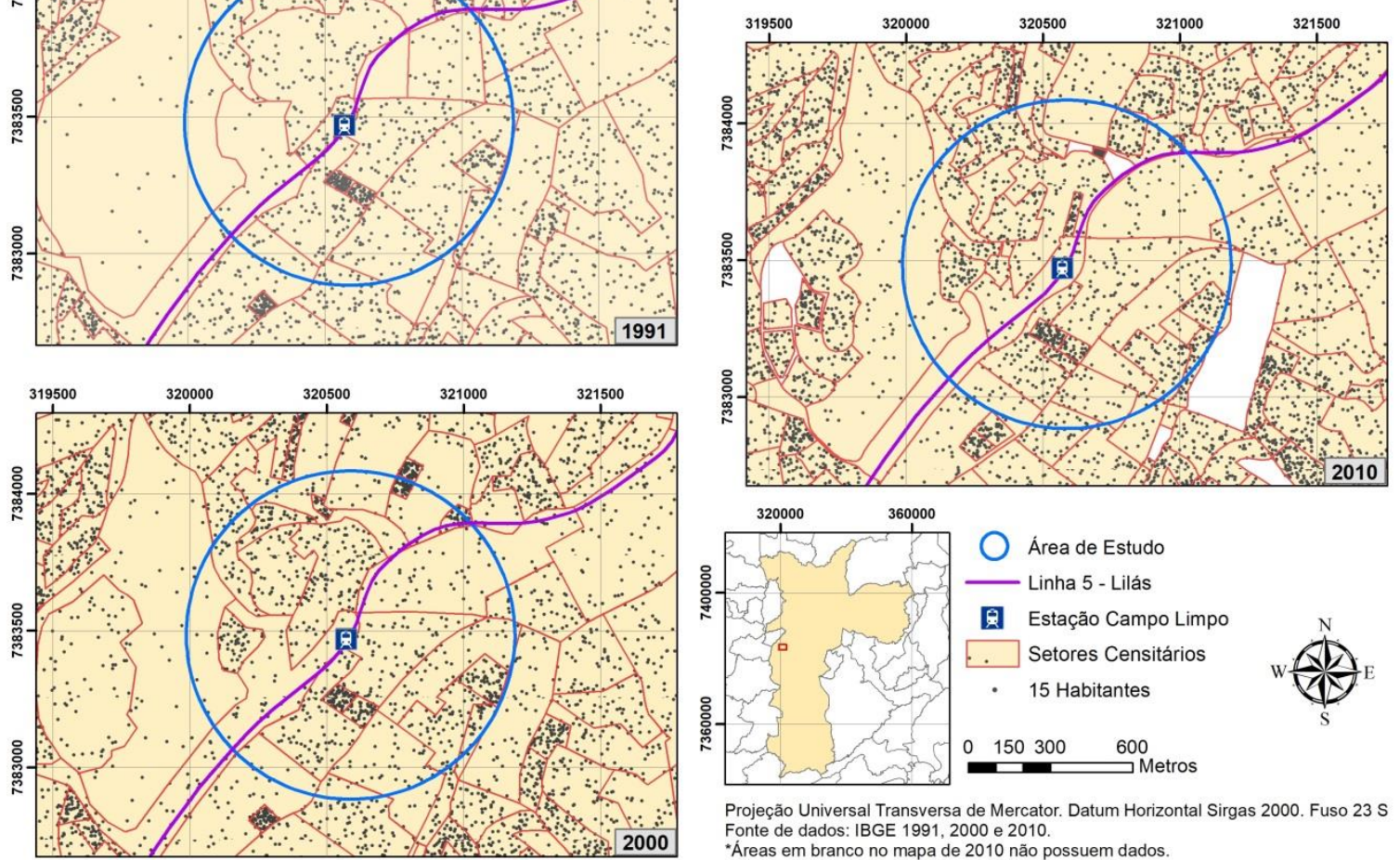

Fonte: Organização dos autores

O desmembramento dos setores censitários, no período, pode ser considerado um indicador de aumento populacional da área de estudo. Essa mudança pode ser visualizada: 1) nas porções norte/noroeste da estação, com maior fragmentação dos setores, o crescimento dos edifícios, majoritariamente no bairro Horto do Ipê; 2) nas regiões sul/sudeste, com pequenas fragmentações e predomínio de telhado de cerâmica e baixa verticalização.

É também possível ressaltar o aumento na concentração de habitantes, entre 1991 e 2000. Como esperado, houve acréscimo populacional durante a obra e depois da inauguração do metrô Campo Limpo (20/10/2002). A figura 9a mostra o aumento da quantidade de pessoas residentes nos setores censitários integralmente contidos no interior do raio de 600 metros. Observa-se a discrepância entre os anos de 1991 e 2000: houve um acréscimo de 17,68\% nestes setores, mas apenas 0,57\% entre os anos de 2000 e 2010. 
A figura 9b também mostra o aumento linear da população no entorno da estação. Diferentemente da 9a, ilustra os setores interseccionados com a área de estudo. Entre 1991, antes da decisão de construir a estação, e 2010, quando a estação já estava operando, houve um aumento populacional de $23 \%$. A indicação desses dois gráficos é coerente com as informações da figura 8 e com o aumento da classe telhado de concreto, da figura 7.

Figuras 9a e 9b - Quantidade de residentes dos setores censitários totalmente inseridos

(a) e interseccionados pelo raio de 600 metros (b)
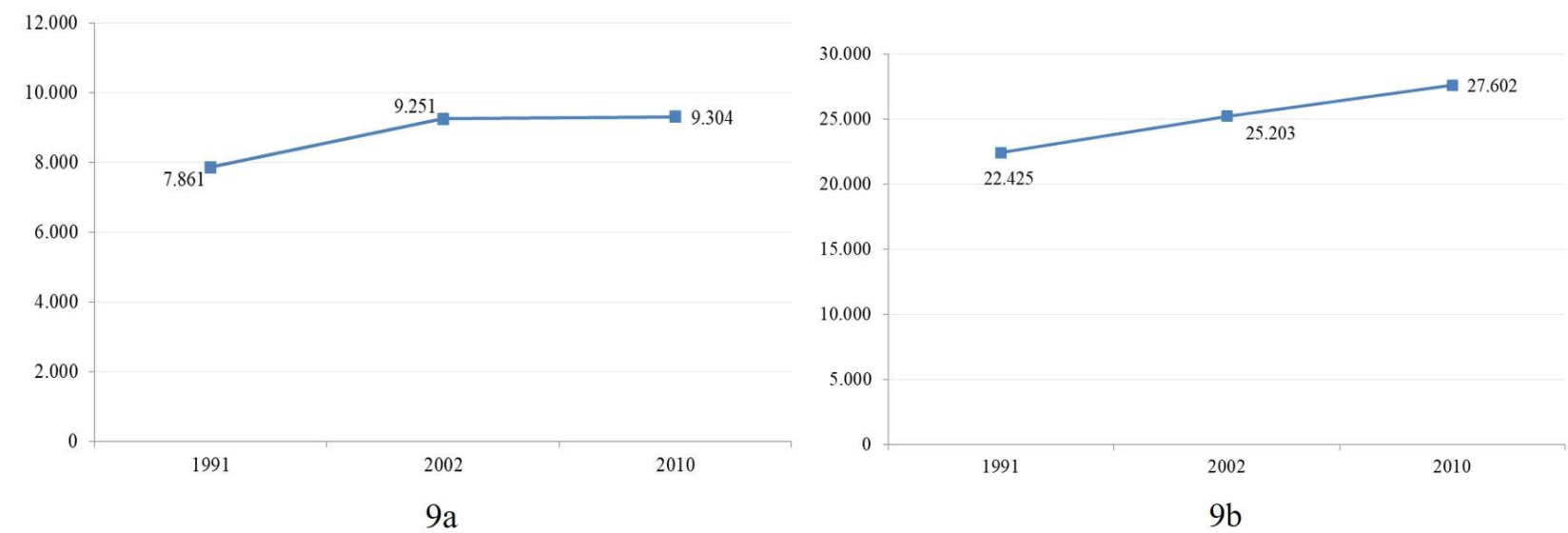

Fonte: Organização dos autores

Entretanto, é importante considerar que o aumento populacional no entorno das estações de Metrô não é uma regra. Estudos realizados por Macêdo (2010) e Gutierres (2013) indicaram a redução da população no entorno das estações analisadas. Os referidos autores constataram o crescimento do setor de comércio e serviços, e a elevação do número de moradias de alto padrão.

A figura 10 mostra a distribuição dos lançamentos imobiliários residenciais em dois raios de ação: 600 (direto) e 1000 metros (área de controle). Representa a quantidade de unidades lançadas por ano dentro da área de 1000 metros. Das 4881 unidades lançadas em 19 anos, destaca-se o número de lançamentos de 2001 (656 ou 13,4\% do total), ano anterior à abertura da estação. Embora os anos 2009 e 1999 também se destaquem, considera-se que a elevação de 2011 poderia ser associada à inauguração da estação Pinheiros, da Linha 
4 Amarela do Metrô. A integração da linha Lilás 5, via linha Esmeralda, com a linha Amarela proporcionou que seus usuários se deslocassem até o centro da cidade de São Paulo somente sobre trilhos.

Figura 10 - Quantidade de unidades lançadas por ano para cada raio de ação

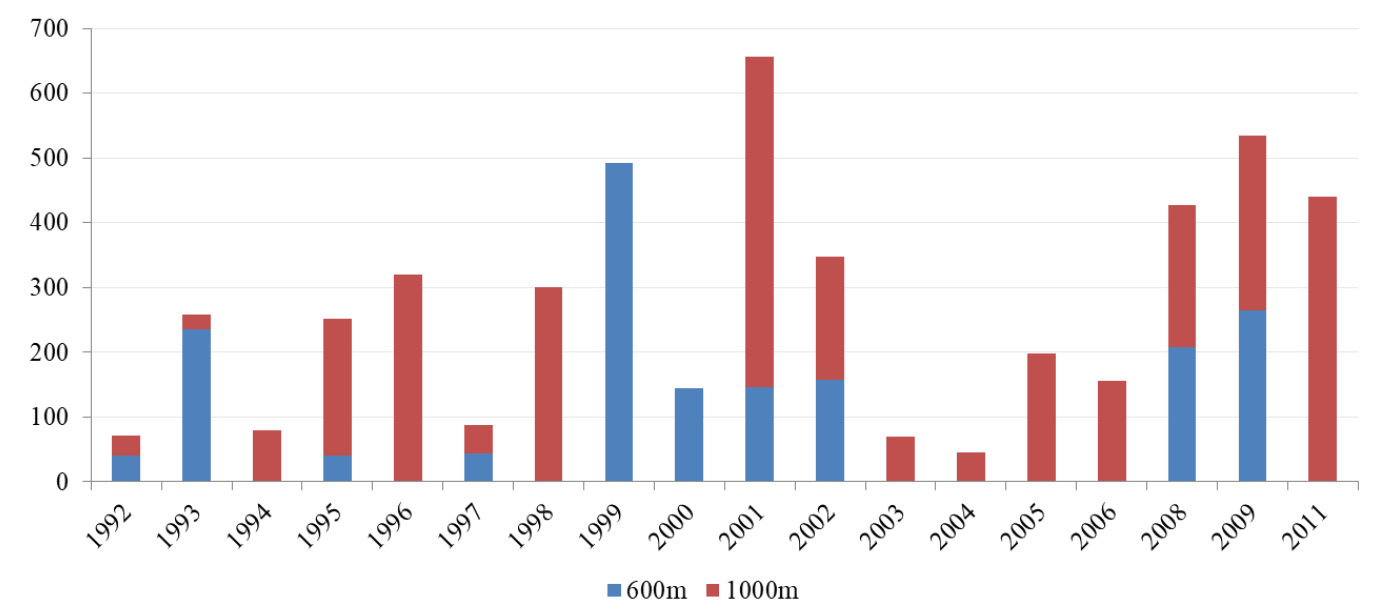

Fonte: Organização dos autores

A figura 11 mostra a localização dos lançamentos residenciais no entorno da estação do Campo Limpo, nas duas faixas de análise. Analisando sua distribuição, nota-se que a maioria dos lançamentos aconteceu fora de raio direto de 600 metros, pois houve mais lançamentos na faixa entre 600 e $1000 \mathrm{~m}$. 
Figura 11 - Localização dos lançamentos imobiliários

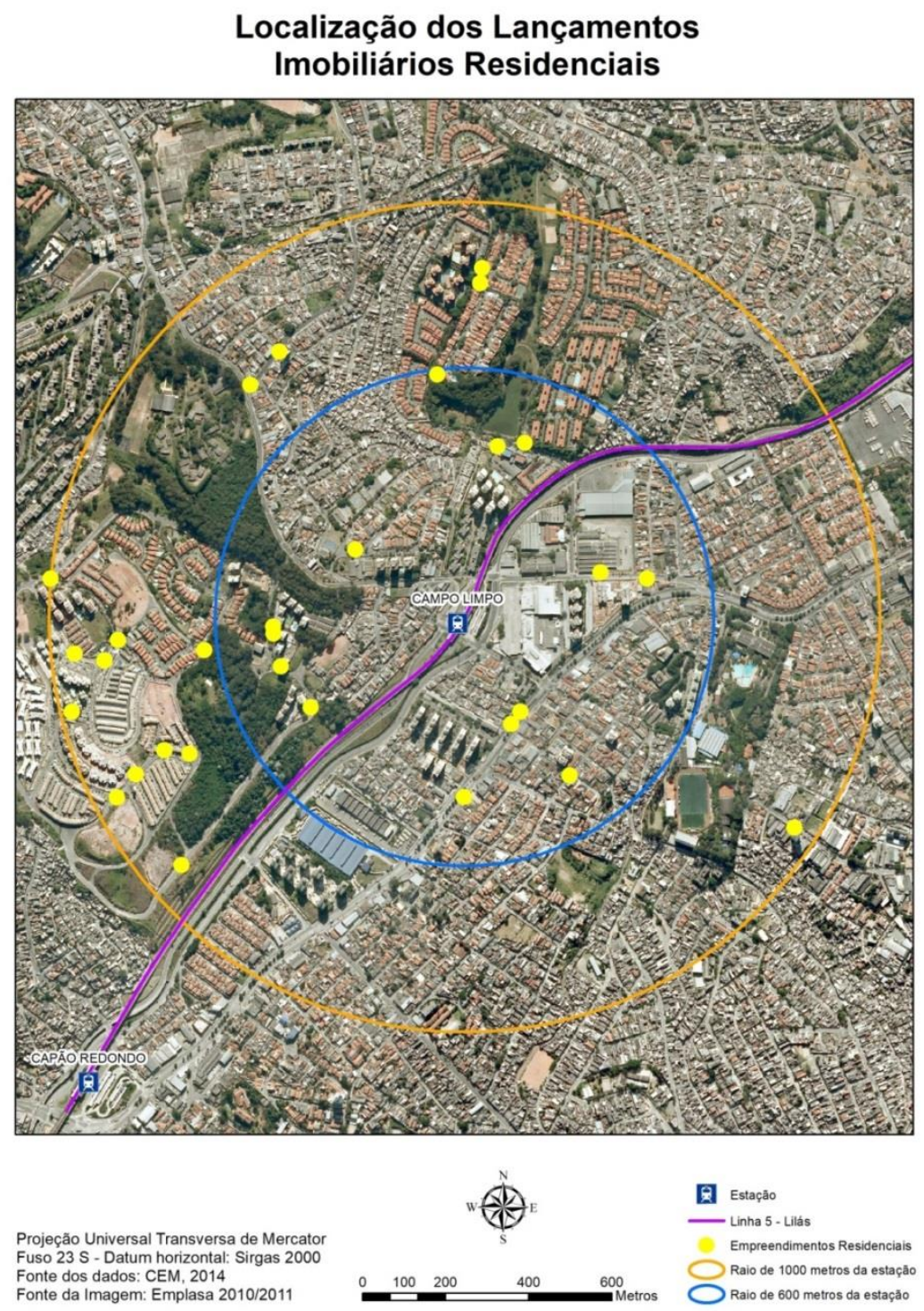

Fonte: Organização dos autores

A figura 12 ilustra a quantidade de unidades imobiliárias lançadas entre 1992 e 2011 (4881) no interior do raio de 1000m. Destaca-se o número de lançamentos de 2001, com 656 (13,4\% do total), ano anterior à abertura da estação. Os anos de 2009, 1999 e 2011 também se destacam. A elevação de 2011 pode estar associada à inauguração da estação Pinheiros da Linha 4 Amarela do Metrô, proporcionando aos usuários da Linha 5 acessar o centro da cidade exclusivamente sobre trilhos. 
Figura 12 - Quantidade de unidades imobiliárias residenciais lançadas por ano (até $1000 \mathrm{~m})$

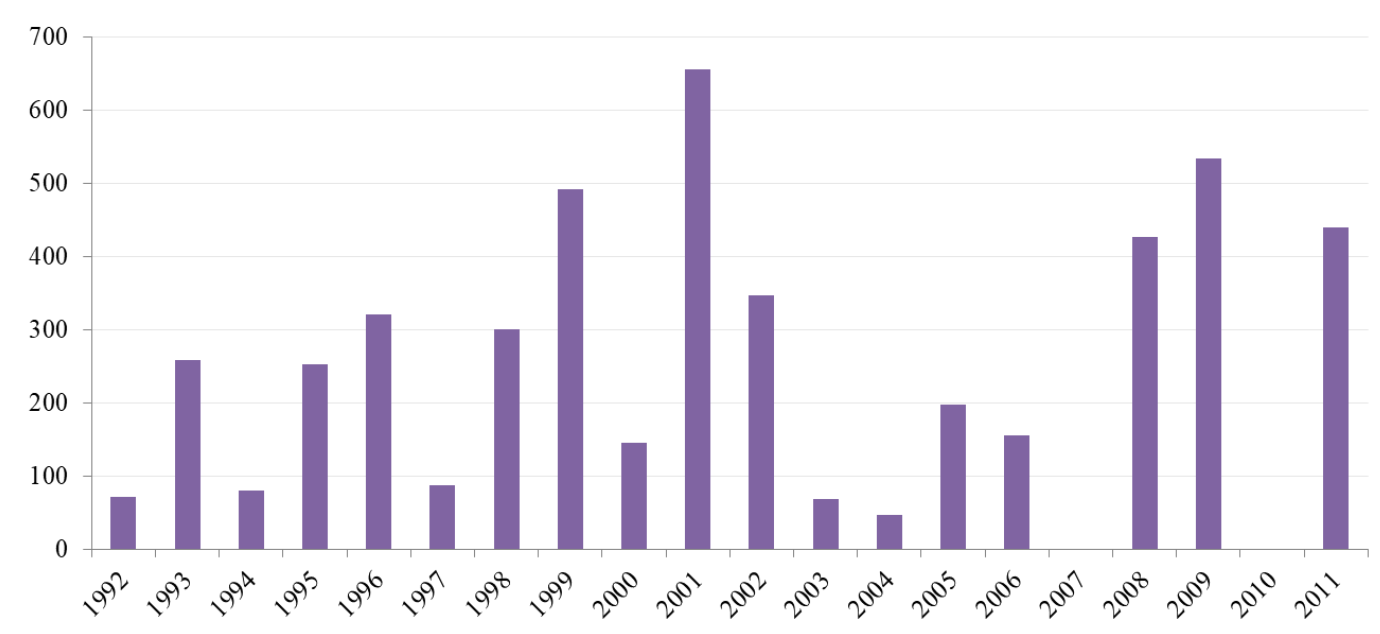

Fonte: Organização dos autores

Embora o adensamento populacional no interior raio de $600 \mathrm{~m}$ da estação não seja, comparativamente, mais elevado, houve uma verticalização residencial nos anos de 2008 e 2009, com o lançamento do condomínio clube Brink. A figura 13 mostra o início do processo de verticalização, com o lançamento de 1557 unidades, entre 2006 e 2011. Mesmo com a predominância dos apartamentos, foi possível contextualizar dois momentos: a) década de 1990, com mais lançamentos horizontais, originários da consolidação do bairro Morumbi Sul (unidades unifamiliares de alto padrão); b) após 2000, com o crescimento do bairro Horto do Ipê, com maior número de lançamentos verticais, mas com tamanho menor, quando comparados às unidades horizontais e verticais do Morumbi Sul (média de $125 \mathrm{~m}^{2}$ de área útil das casas e $73 \mathrm{~m}^{2}$ dos apartamentos).

Figura 13 - Quantidade de unidades imobiliárias residenciais por tipo de lançamentos 


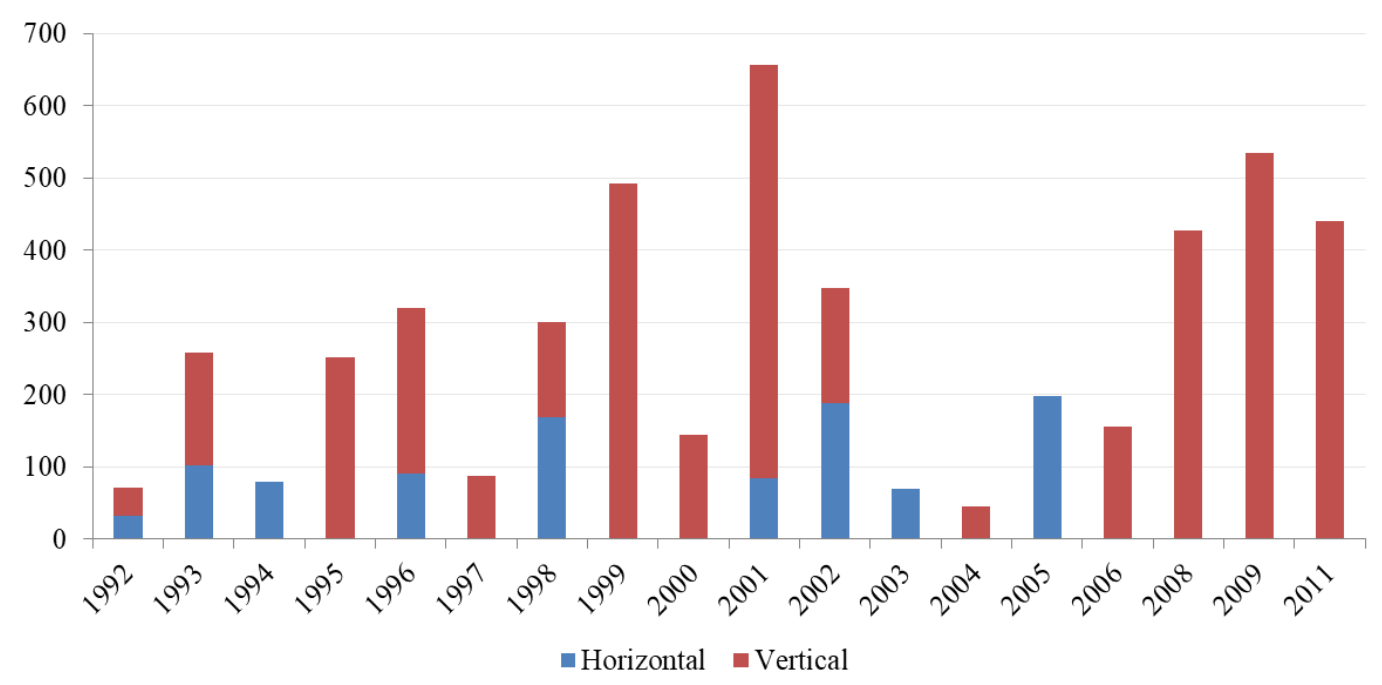

Fonte: Organização dos autores

A figura 14 aponta a evolução do preço do metro quadrado médio das unidades, na época de lançamento, dentro do raio de 1000 metros.

Figura 14 - Quantidade de lançamentos imobiliários e o preço do metro quadrado

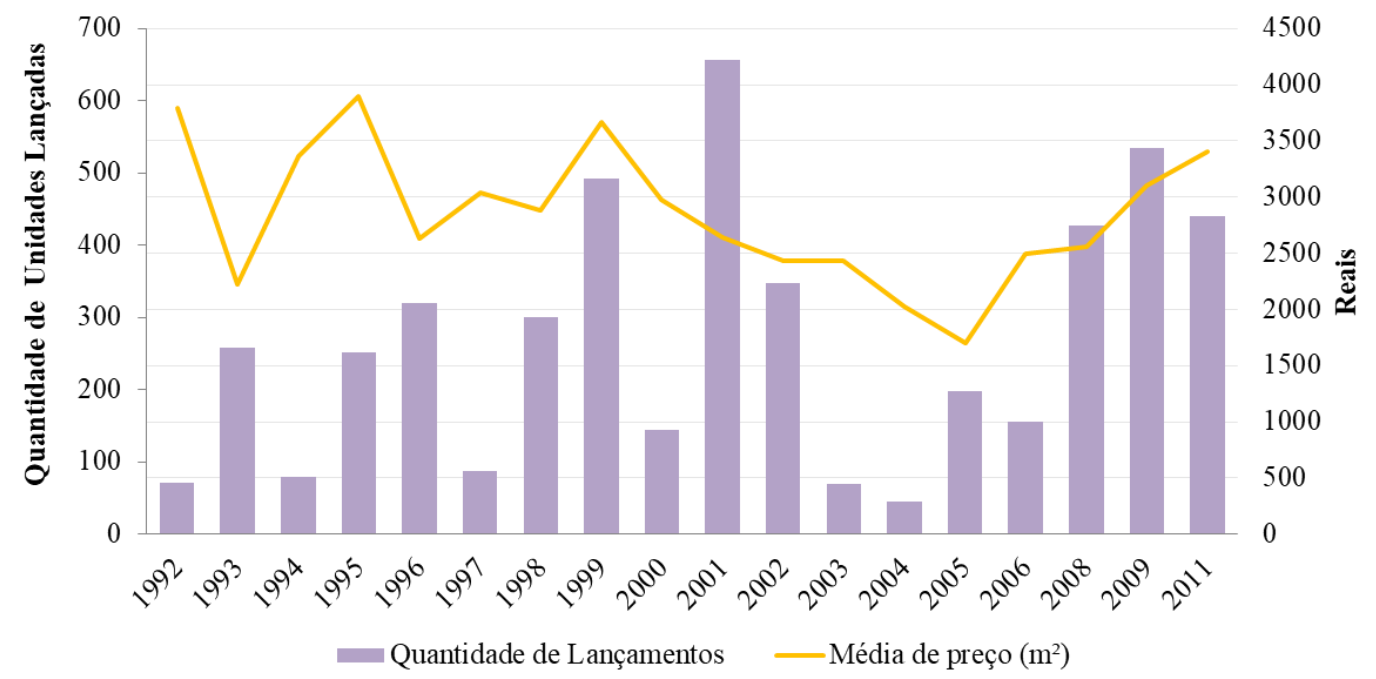

Fonte: Organização dos autores

Em valores atualizados, de acordo com o IGP-DI de 2011, houve uma desvalorização do preço dos imóveis a partir de 1999 e uma revalorização após 2005. Outro indicador interessante é a variação nos preços em relação à inauguração da estação. Essas 
constatações podem ser relacionadas com as análises anteriores: 1) por serem maiores, os lançamentos horizontais pressionaram os preços do metro quadrado para cima; 2) com a inauguração da estação e o início da verticalização, com apartamentos menores e menos sofisticados, o preço do metro quadrado caiu; e 3) com a chegada de condomínios verticais mais luxuosos, como o Brink, houve o crescimento do valor do metro quadrado na região, entre os anos de 2008 e 2011.

\section{DISCUSSÃO}

Considerando o contexto do mapeamento temporal da cobertura da terra e a metodologia adotada, a classificação permitiu identificar e mensurar elementos urbanos de menor dimensão, ainda que tenha havido confusão entre algumas classes. Beltrame (2008) e Penteado et al. (2007) também identificaram misturas de classes, tais como: 1) telhado de concreto/amianto e asfalto, pela pequena diferença espectral; 2) telhado de cerâmica e solo exposto, pois algumas faces claras da cobertura se confundiram com o solo argiloso; e 3) cobertura arbórea e água, pela semelhança das respostas espectrais.

Destaca-se que o índice Kappa da classificação de Beltrame (2008) foi igual ao da fotografia aérea de 2010, calculado nessa pesquisa $(0,74)$. Ainda que o índice Kappa da imagem de 2002 tenha sido inferior (0,62), foi possível mapear a cobertura da terra e compará-la com a de 2010. O resultado demonstrou poucas diferenças entre 2002 e 2010. A classe telhado de concreto/amianto foi a mais significativa, com aumento de 4,5\%. Ao contrário do que se esperava, os resultados da classificação de imagens não indicaram mudanças relevantes na cobertura da terra no intervalo analisado.

Os dados populacionais e de lançamentos imobiliários, nos três cenários: antes, durante e depois da construção da estação Campo Limpo se mostraram mais esclarecedores. Constatou-se: 1) as oscilações discretas da população e do adensamento imobiliário no raio de 600 metros, possivelmente relacionado ao crescimento da classe "concreto", e 2) aumento do número de habitantes e dos lançamentos imobiliários no raio entre 600 e 1000 metros. 
Esses elementos fortaleceram a interpretação de que as mudanças decorrentes da instalação de uma estação metroviária podem exceder o entorno imediato de 600 metros. De certa forma, essa perspectiva pode ser considerada coerente à de Macêdo (2010), cujo diagnóstico indica mudanças significativas no adensamento imobiliário, especialmente nos bairros de classe média e no entorno imediato (600 metros) das estações. A autora observou ainda o crescimento dos lançamentos verticais e a queda dos residenciais horizontais após a abertura da estação, bem como a substituição de armazéns e indústrias. Assim, ainda que a densidade de imóveis no entorno imediato da estação de Campo Limpo tenha aumentado pouco, a quantidade de lançamentos residenciais verticais cresceu, principalmente após 2006 (ver figura 13). Também se constatou a transformação do uso industrial (armazéns) em áreas residenciais, comerciais e de serviços.

Outro aspecto inesperado, mas relevante, foi a redução do preço do metro quadrado após a inauguração da estação. Embora essa redução possa ser também relacionada ao tamanho e padrão dos imóveis lançados (entre os anos de 2000 a 2006), o relatório da TCRP (1996) indica que, para o valor das residências aumentar, o sistema de transporte deve estar bem desenvolvido e integrado aos demais módulos de transportes. Lima Neto (2011) também contribuiu para a essa reflexão, pois constatou a valorização imobiliária de terrenos de uso misto (comercial e residencial), em detrimento dos residenciais, nas proximidades das estações metroviárias em Brasília.

Outro fator que corrobora o estudo da TCRP (1996), e que pode ser vinculado ao baixo número de lançamentos imobiliários do entorno imediato, são as características técnicas da linha. Em 2010, a extensão e o número de estações da Linha 5 Lilás e suas conexões estavam aquém do previsto. Na época, a linha só fazia conexão com a 9-Esmeralda CPTM e, a última estação, Brooklin, ficava distante do centro do município. Outra possibilidade, não investigada neste estudo, pode estar relacionada aos efeitos negativos da proximidade das residências à estação, como os aumentos do ruído e do tráfego de veículos, mencionados por Lima Neto (2011) e Gualda (1994).

Também é importante resgatar as abordagens de Villaça (1978) e Gualda (1994) que, em termos gerais, afirmam que a instalação de sistemas de transportes provocam mudanças no uso e cobertura da terra e na valorização do solo, por aumentar a acessibilidade aos 
demais lugares da cidade. Em nosso objeto de estudo, o mapeamento do entorno imediato indicou pouca variação. Em contrapartida, ficaram comprovadas as mudanças demográficas e o adensamento imobiliário, em uma área de abrangência maior, após a instalação da estação do Campo Limpo.

Finalmente, é importante ponderar que as análises das imagens de satélite e dos dados imobiliários foram úteis, mas podem ser insuficientes para determinar a dinâmica do processo de mudança do uso da terra no entorno da estação do Metrô. A conjuntura macroeconômica, o zoneamento, as decisões políticas ou vinculadas ao mercado imobiliário devem ser considerados em um estudo mais completo.

Assim, os dados indicaram que a estação do Campo Limpo contribuiu para as transformações da cobertura da terra, mas não foi possível quantificar sua influência. Além disso, argumenta-se que a sua localização periférica, sem ligação direta com o centro (na época), e uma conexão única com a linha de trem urbano, seriam determinantes para atenuar a importância da acessibilidade nas mudanças da cobertura da terra no raio de 600 metros da estação.

\section{CONSIDERAÇÕES FINAIS}

A análise conjunta da classificação de imagens de satélite, dos dados populacionais e de lançamentos imobiliários permitiu avaliar as transformações da estrutura urbana do entorno da estação metroviária do Campo Limpo - SP. Entre 2002 e 2010, as classes de cobertura da terra que mais aumentaram foram: vegetação arbórea $(4,89 \%)$ e telhado de concreto/amianto (4,54\%). As que perderam mais representatividade foram sombra (-7,42\%) e solo exposto (5,77\%). Observou-se também que, em 2005, houve uma elevação do número de lançamentos imobiliários, na faixa entre 600 e 1000m da estação. Comparativamente, houve predomínio dos condomínios verticais, redução da área e do preço do metro quadrado dos imóveis no referido período.

Entre 1991 e 2010, antes da decisão de construir e após sua inauguração, houve um aumento populacional de $23 \%$. Ao contrário do que se esperava, constatou-se que as 
transformações do uso da terra na área de influência direta da estação foram modestas (600m). No entanto, como as modificações foram mais relevantes na faixa entre 600 e 1000m, ficou caracterizado que a influência de uma estação metroviária excedeu o entorno imediato de 600m.

Além de ampliar o número de estações e de variáveis analisadas, acredita-se que as alternativas mais promissoras de continuidade da pesquisa são a classificação orientada ao objeto e o uso de imagens do sensor LiDAR (Light Detection and Ranging). Os métodos baseados em Análise de Imagens Baseada em Objetos Geográficos permitem elaborar classificações a partir da textura e do padrão espacial dos objetos, melhorando a qualidade e otimizando o processo de classificação. O uso de dados do sensor LiDAR contribuiria neste tipo de classificação de cobertura da terra, pois fornece atributos tridimensionais e permite a análise do processo de verticalização urbana, característica frequente após a construção de uma estação metroviária.

\section{REFERÊNCIAS}

ARAUJO, A. S.; LUCHIARI, A. Elaboração de mapa de cobertura da terra intraurbana com base em análise baseada em objetos (OBIA) para inferências sobre o uso na cidade de Marília/SP. Geografia, v.41, n.2, p. 241260, 2016.

ARAUJO, A. S.; QUEIROZ, A. P. Spatial Characterization and Mapping of Gated Communities. International Journal of Geo-Information, v.7, n.7, p.1-22, 2018. DOI: https://doi.org/10.3390/ijgi7070248

ARW (ATIS REAL Weatheralls) and UCL (University College London) Land Value and Public Transport Literature Review, for the ODPM and the RICS, 2002. November Disponível em: http://www.rics.org/resources/research/land2.html. Acesso em: 27 fev. 2019.

AVELAR, S.; ZAH, R.; TAVARES, C.C. Linking socioeconomic classes and land cover data in Lima, Peru: Assessment through the application of remote sensing and GIS. International Journal of Applied Earth Observation and Geoinformation, v.11, n.1, p.27-37, 2009. DOI: https://doi.org/10.1016/j.jag.2008.05.001

Beltrame, A. M. K. Mapeamento da Cobertura do solo ao longo da faixa de domínio do trem metropolitano: linha F em São Paulo. 2008. 104p. Dissertação (Mestrado em Engenharia) - Universidade de São Paulo, São Paulo.

BRITES, R. S.; BIAS, E.S.; ROSA, A. N. C. S. Classificação por Regiões. In: MENESES, P. R.; ALMEIDA, T. (orgs). Introdução ao Processamento de Imagens de Sensoriamento Remoto. 1. ed. Brasília: Conselho Nacional de Desenvolvimento Científico e Tecnológico, 2012. p.209-220.

CALVO, F. J.; OÑA, J.; ARÁN, F.; NASH, A. Light Rail Transit Experience in Madrid, Spain: Effects on Population Settlement and Land Use. Transportation Research Record, v. 2353, n.1, p.82-91, 2013. DOI: https://doi.org/10.3141/2353-08 
CERVERO, R. Transit-based housing in California: evidence on ridership impacts. Transport Policy. v.1, n.3, p.174-183, 1994. DOI: 10.1016/0967-070X(94)90013-2

CERVERO, R.; DUNCAN, D.M. Benefits of Proximity to Rail on Housing Markets. Journal of Public Transportation, vol. 5, n. 2, p. 1-18, 2002. DOI: https://doi.org/10.5038/2375-0901.5.1.1

CONGALTON, R. G.; GREEN, K. Assessing the Accuracy of Remotely Sensed Data: principles and practices. 2. ed. New York: Taylor and Francis, 2009.

DARROCH, N.; BEECROFT, M.; NELSON, J.D. A conceptual framework for land use and metro infrastructure. Infrastructure Asset Management, v.3, n.4, p.123-132, 2016. DOI: http://dx.doi.org/10.1680/jinam.16.00008

DORANTES, L.M.; PAEZ, A.; VASSALLO, J. Analysis of House Prices to Assess Economic Impacts of New Public Transport Infrastructure: Madrid Metro Line 12. Transportation Research Record: Journal of the Transportation Research Board, v.2245, n.2, p.131-139, 2011. DOI: https://doi.org/10.3141/2245-16

DU, C.; MULLEY, C. The short-term land value impacts of urban rail transit: quantitative evidence from Sunderland, UK. Land Use Policy, v.24, n.1, p.223-233, $2007 . \quad$ DOI: https://doi.org/10.1016/j.landusepol.2005.12.003

GONÇALVES, J. A. M.; PORTUGAL, L. S. Classificando Estações Metro-Ferroviárias como Polo Promotor do Desenvolvimento Socioeconômico. $4^{\circ}$ Concurso de Monografias CBTU - A Cidade nos Trilhos. 2008.

GUALDA, N. D. F. Impactos da evolução tecnológica dos transportes na sociedade: uma visão sistêmica. Estudos Urbanos, v. 8, p.17-28, 1994.

GUTIERRES, D. M. M. Análise da Evolução da demanda por transportes associada à implantação de estações de Metrô. 2013. 84p. Dissertação (Mestrado em Engenharia) - Universidade de São Paulo, São Paulo.

HESS, D. B. Impact of Proximity to Light Rail Rapid Transit on Station-Area Property Values in Buffalo, New York. Urban Studies, v.5, n.6, p.1041-1068, 2007. DOI: https://doi.org/10.1080/00420980701256005

JUN, M.J.; CHOI, K.; JEONG, J.E.; KWON, K.H.; KIM, H.J. Land use characteristics of subway catchment areas and their influence on subway ridership in Seoul. Journal of Transport Geography, v. 48, p. 30-40, 2015. DOI: https://doi.org/10.1016/j.jtrangeo.2015.08.002

KRESSLER, F. P.; STEINNOCHER, K. Image data and LIDAR - an ideal combination matched by object-oriented analysis. Geographic Object-Based Image Analysis, v.36, n.1, p. 36-60, 2006.

LANDIS, R. J.; KOCH, G. G. The Measurement of Observed Agreement for Categorial Data. Biometrics, v.33, n.1, p.159-174, 1977.

LIMA NETO, V. C. O Efeito dos investimentos em transporte público no valor dos imóveis: o caso do distrito federal. Boletim regional, urbano e ambiental, IPEA. v.6, p.165-175, 2011.

LIU, X.; HE, J.; YAO, Y.; ZHANG, J.; LIANG, H.; WANG, H.; HONG, Y. Classifying urban land use by integrating remote sensing and social media data. International Journal Geographical Information Science, v.31, n.8 p.1675-1696, 2017. DOI: https://doi.org/10.1080/13658816.2017.1324976

LOMBARDO, M. A.; MACHADO, R.P.P. Aplicação das técnicas de Sensoriamento Remoto e Sistemas de Informações Geográficas nos Estudos Urbanos. Revista do Departamento de Geografia, v.10, p.5-11, 2011. DOI: https://doi.org/10.7154/RDG.1996.0010.0001

LUCHIARI, A. Imagens da metrópole. In: CARLOS, A. A.; OLIVEIRA, A. U. (orgs.) Geografias de São Paulo: representação e crise da metrópole. São Paulo: Editora Contexto, 2004. p. 231-246

MACÊDO, N. C. Uma análise sobre os impactos decorrentes da inserção de estações metroviárias em áreas urbanas: contribuição conceitual e metodológica através de estudos de casos na cidade de São Paulo. 2010. 164p. Dissertação (Mestrado em Engenharia) - Universidade de São Paulo, São Paulo.

MENESES, P.R.; ALMEIDA, T. Introdução ao processamento de imagens de Sensoriamento Remoto. 1. ed. Brasília: Conselho Nacional de Desenvolvimento Científico e Tecnológico, 2012. 
NIGRIELLO, A. O Valor do Uso do Solo e sua relação com a acessibilidade. 1977, 238p. Dissertação (Mestrado em Engenharia) - COPPE - Universidade Federal do Rio de Janeiro, Rio de Janeiro.

NOVO, E.M.L.M.; PONZONI, F. J. Introdução ao Sensoriamento Remoto. São José dos Campos: Instituto Nacional de pesquisas Espaciais, 2001.

PAGLIARA, F.; PAPA, E. Urban rail systems investments: an analysis of the impacts on property values and residents' location. Journal of Transport Geography, v.9, n.2, p.200-211, 2011. DOI: https://doi.org/10.1016/j.jtrangeo.2010.02.006

PENTEADO, D. R.; MARQUES, M. L.; GUEDES, A. C. M.; GIBERTI, P. P. C. Classificação orientada por regiões em imagem IKONOS para a identificação e análise da cobertura do solo urbano de Ubatuba (SP). In: XIII SIMPÓSIO BRASILEIRO DE SENSORIAMENTO REMOTO, 2007, Florianópolis. Anais... Florianópolis, 2007. p.661-669.

SANTOS, R. F. Planejamento Ambiental: Teoria e Prática. São Paulo: Oficina de Textos, 2004.

SONG, Y.; KIM, H. Evolution of Subway Network Systems, Subway Accessibility, and Change of Urban Landscape: A Longitudinal Approach to Seoul Metropolitan Area. International Journal of Applied Geospatial Research, v.6, n.2, p.53-76, 2015. DOI: http://dx.doi.org/10.4018/ijagr.2015040104

SOUSA, I, M. Sensoriamento Remoto Orbital Aplicado a Estudos Urbanos. São José dos Campos: Instituto Nacional de Pesquisas Espaciais, 2012

SOUZA, I. M.; PEREIRA, M. N.; GARCIA, L. M. F.; KURKDJIAN, M. L. N. O. Mapeamento do uso do solo urbano através da classificação por regiões baseada em medidas texturais. In: XI SIMPÓSIO BRASILEIRO DE SENSORIAMENTO REMOTO. 2003, Belo Horizonte. Anais... Belo Horizonte, 2003. p.1967-1968.

STÜRCK, J.; SCHULP, C.J.E.; VERBURG, P.H. Spatio-temporal dynamics of regulating ecosystem services in Europe - the role of past and future land use change. Applyed Geography, v.63, n.1, p.121-135, 2015. DOI: https://doi.org/10.1016/j.apgeog.2015.06.009

TCRP - Transit Cooperative Research Program. Transit and Urban Form. TCRP Report 16. v.1. Washington: National Academy Press, Transportation Research Board, 1996.

VILLAÇA, F. Uso do Solo Urbano. São Paulo: Fundação Prefeito Faria Lima, 1978.

VOLPE, L. L. Análise da paisagem no entorno dos eixos viários: o exemplo do Rodoanel Mario Covas na RMSP. 2009. 208p. Dissertação (Mestrado em Geografia Física) - Universidade de São Paulo, São Paulo, São Paulo.

YIGITCANLAR, T.; KAMRUZZAMAN, M. Investigating the interplay between transport, land use and the environment: a review of the literature. International Journal of Environmental Science and Technology, v.11, n.8, p.2121-2132, 2014. DOI: https://doi.org/10.1007/s13762-014-0691-z

ZHAO, J.; DENG, W; SONG, Y.; ZHU, Y. What influences metro station ridership in China? Insights from Nanjing. Cities, v.35, p.114-124, 2013. DOI: https://doi.org/10.1016/j.cities.2013.07.002 